\title{
Expected Time to Employment as a Function of Labor Market Size: A Theoretical Note*
}

\author{
Peter V. Schaeffer and Tesfa G. Gebremedhin ${ }^{+}$
}

ABSTRACT. When job prospects are uncertain, labor market size matters even when labor and jobs, respectively, are homogenous. The expected time to employment and its standard deviation may differ systematically with labor market size and create incentives for agglomeration.

Keywords: Expected unemployment duration, labor market size, agglomeration

JEL Classifications: $J 64, J 68, R 12$

\section{INTRODUCTION}

Adam Smith (1776) famously observed that the division of labor is limited by the extent of the market; Marshall (1890) established the importance of localization and urbanization economies (agglomeration economies). Contributions to the literature concerning the size of labor markets since then have focused mostly on the effects of agglomeration economies, but the division of labor as one of the foundations of modern economics (Myers, 1983) is implicit in all of them.

In this article, we analyze the relationship between labor market size and expected unemployment duration. Unemployment duration is an important measure of labor market performance (Fields, 1976). Constraints on the life-time duration of welfare benefits became more stringent with the passage of the Personal Responsibility and Work Opportunity Reconciliation Act of 1995 (U.S. Library of Congress, 1995; see also Bartik, 2002; Dilger et al., 2004), and employers might interpret long unemployment spells as negative signals about workers' quality (Berkovitch, 1985; Lockwood, 1991). Hence, workers have good reasons to be concerned about the duration of their unemployment and to consider it when making location decisions and/or choosing a profession.

Many scholars have studied unemployment duration (e.g., Akerlof and Main, 1981). Gan and Zhang (2006) investigate the relationship between market size and unemployment duration, as we do. They find that unemployment duration in large labor markets is shorter than in smaller ones. Theirs is a search theoretic model where the result depends on the presence of agglomeration economies which facilitate the search and improve job matches. An earlier contribution by Lockwood (1991) shares a similar modeling philosophy, but does not include market size. It does, however, include information about workers' skills. Since firms can screen workers, previous unemployment duration sends a negative signal about a worker's skill level. Other related empirical studies (e.g., Arulampalam and Stewart, 1995; Blanchard and Diamond, 1994) also exclude labor market size. Many other related studies of geographical variations in unemployment use unemployment rates and not duration (e.g., Neumann and Topel, 1991; Karanassou and Snower, 1998; Bande and Karanassou, 2007). Rogerson, Shimer, and White (2005) present a survey of search theoretic models that includes a discussion of search duration under different conditions. All of these

\footnotetext{
* We acknowledge comments by Gebremeskel Gebremeriam, Haixiao Huang, Scott Loveridge, and Anthony E. Smith, and this journal's referees. We also owe thanks to the editors! The usual caveat applies.

+ Schaeffer and Gebremedhin are Professors in the Division of Resource Management, West Virginia University, P.O. Box 6108, Morgantown, WV 26506-6108. E-mail: Peter.Schaeffer@mail.wvu.edu. 
contributions attribute differences in unemployment rates or unemployment duration to the heterogeneity of labor and/or employers.

Obviously, heterogeneity of labor and employers causes different labor market outcomes among participants, and the study of such heterogeneity is critical to our understanding of labor markets and the design of labor market policies. This note demonstrates how in the presence of uncertainty, size can matter even in the absence of agglomeration effects or any other differences between two labor markets. We are asking if the expected unemployment duration would be the same even if labor markets were identical in every respect except size, and labor and employers, respectively, were both homogenous. We will show that the answer can be No.

To understand the issue intuitively, consider a job seeker looking at two locations. In one location, the unemployment rate is five percent and in a given week there are 100 relevant job openings she can apply for. Assume that the second location is a smaller labor market with unemployment at two percent. In a given week there are five relevant job openings. Clearly, there are more potential opportunities in the larger market, but there will also be more competition for available jobs. Thus, the smaller market can compensate for having fewer job openings during a given time period by offering better odds. This tradeoff opportunity is exhausted, however, once the probability of obtaining the next available job reaches 1 .

The rest of this note is organized as follows. In the next section we present the model. Section 3 contains the analysis of the effect of labor market size on expected unemployment duration. In Section 4 we take a brief look at the standard deviation of the expected unemployment duration as a measure of risk. Finally, Section 5 provides a summary and conclusions.

\section{THE MODEL}

Success in obtaining a job depends on the frequency with which jobs become available and the number of other workers competing for the same job. To control for differences in workers' qualifications we assume that all have identical qualifications. Hence, employers are indifferent to whom they hire. This assumption focuses attention solely on the effect of labor market size on the time to obtaining a job. We assume that job openings are uniformly distributed over time, so that the expected time between them is fixed. This assumption implies that jobs are not seasonally or otherwise unevenly distributed over time. Since all jobs are identical, an applicant who is offered a job will immediately accept it and an available job is filled instantaneously. We also assume that search costs, including the cost of moving to another labor market, and any other transactions costs, are zero, so as to eliminate any influence on the results other than labor market size.

We will use the following notation:

$\lambda$ expected length of time between job offers. This is a stochastic variable. Its distribution is assumed to be uniform over time.

$T$ number of periods of length $\lambda ; t=1,2,3, \ldots$

$\Lambda$ time before a position is obtained (unemployment duration). This expected unemployment duration, $\mathrm{E}[\Lambda]$, will be defined below.

$U$ number of unemployed workers competing for jobs. We assume that the economy is in a steady state and hence that this number is constant and reflects the natural rate of unemployment. 
$L$ measure of labor market size, consisting of those currently employed plus those looking for employment. We assume that $L$ is constant.

$p$ probability that an applicant is offered a vacant job. Since all jobs are identical, the probability that a worker accepts the offer is 1 . Therefore, $p$ represents the joint probability of being offered and accepting a job. Because of our assumptions, $p$ is constant.

We make the following assumptions about functional relationships.

$$
p=p(U)
$$

The justification is that with more workers unemployed, competition for available job openings is stiffer.

$$
\lambda=\lambda(L), \frac{d \lambda}{d L}<0
$$

Job openings occur as a result of job turnover because of retirement. Because we assume labor markets that are in a steady state, the turnover rate is constant and large labor markets will therefore have more frequent job openings. While this is a logical conclusion of our assumptions and necessary to limit the focus to labor market size alone, it does not necessarily agree with empirical findings (Bleakley and Lin, 2007; Groen, 2005). Empirical results reflect differences in search efficiency by labor market size, as well as other differences, which we exclude from consideration to focus on the influence of labor market size alone. Therefore, the negative derivative in Equation (2) is justified under our assumptions.

$$
U=U(L), \frac{d U}{d L}>0
$$

Finally, because of the steady state assumption, unemployment is constant and reflects the natural rate of unemployment and the age distribution of the labor force is constant as well (see Mukoyama and Şahin, 2009, for a study of the influence of composition of the labor force on unemployment duration). The steady state assumption also implies that the unemployment rate is constant. Note, however, that the assumption does not imply that the unemployment rates are identical in all labor markets. Instead, they may differ by labor market size.

We assume that the age distribution is independent of labor market size and that the absolute number of unemployed $(U)$ is positively related to the total number of labor market participants $(L)$. In a real world setting where differences among workers and jobs provide incentives to search, larger labor markets, particularly those that are also spatially clustered, may be more efficient and hence may have relatively less unemployment. Nonetheless, even if we consider search efficiency, the assumption that $U$ is positively related to $L$ is reasonable. Because we focus solely on labor market size differences independent of differences in characteristics of jobs or job seekers, spatial or job search efficiency considerations are deliberately excluded from our model, and the assumption is therefore justified.

Given the assumptions, the hiring outcome in each interval is a random event. Since workers are identical, previous failure to obtain a job has no bearing on the probability of future success because it contains no information about a worker's qualifications, but is purely the result of a stochastic process. Since all jobs and all employers are identical, no benefits result from search 
experience. The expected unemployment duration has a binomial distribution because of the assumption that job openings are distributed uniformly over time. Therefore, the expected time until employment is obtained is given by

$$
E[\Lambda]=\sum_{t=1}^{\infty} \lambda t p(1-p)^{t-1}=\frac{\lambda}{p} .
$$

For a job seeker the expected time to employment is positively related to the frequency of job openings $(\lambda)$ and inversely related to the joint probability of being offered and accepting a job $(p)$. This result represents in mathematical form the intuitive statement that small markets can compensate for relative lack of opportunities, represented by $\lambda$, by increasing the probability of success, $p$. Since $p$ and $U$ are inversely related, this tradeoff implies relatively fewer unemployed and a lower unemployment rate in small markets.

\section{LABOR MARKET SIZE AND UNEMPLOYMENT DURATION}

Since $\lambda$ and $p$ are both functions of labor market size, the expected time to employment depends on $L$.

$$
\frac{d E[\Lambda]}{d L}=\frac{\frac{d \lambda}{d L} p-\frac{d p}{d L} \lambda}{p^{2}}
$$

The sign of the derivative is indeterminate because $d \lambda / d L>0$ and $d p / d L=d p / d U d U / d L<0$ for $0<p<1$. This result again reflects that small markets can compensate for offering fewer opportunities by having fewer competitors for them. However, this tradeoff is limited by the constraint $p \leq 1$. When $p=1, d p / d L=0$ and therefore $d E[\Lambda] / d L<0$.

To further investigate the effect of market size on expected unemployment duration for $0<p<1$, we consider a period of a given length, $T$ (e.g., a month). Let $n$ denote the expected number of job openings occurring during this period. For a given value of $p$, the larger the number of job openings during the period, the less likely it is that the worker will still be unemployed at the end of the period. Let us compare two labor markets identical in every respect except the number of offers. Since $\lambda$ is negatively related to $L$ (Equation (2)), Equation (4) shows that to remain equally attractive -compensate for fewer job openings- the smaller labor market must offer unemployed workers a higher probability $p$.

To show the tradeoff, we equate the probabilities of failing to get a job during the period of length $T$ in a small (s) and in a large $(\ell)$ market, respectively: $\left(1-p_{\mathrm{s}}\right)^{n}=\left(1-p_{\ell}\right)^{\alpha n}$. The number of offers is related to $\lambda_{\mathrm{s}}$ as follows: $n=T / \lambda_{\mathrm{s}}$. The parameter $\alpha>1$ indicates by what factor the size of labor market $\ell$ exceeds that of labor market s. Taking the $n^{\text {th }} \operatorname{root}^{1}$ on both sides and rearranging terms, we end up with

$$
p_{\mathrm{s}}=1-\left(1-p_{\ell}\right)^{\alpha} .
$$

${ }^{1}$ Since $n$ falls out of the equation after we take the $n^{\text {th }}$ root, we need not worry about $n$ being a natural number. 
This is the condition under which failure is equally likely in markets $s$ and $\ell$, respectively. Equation (6) shows that for a large value of $\alpha, p_{s}$ has to approach 1 to compensate for the market's relative lack of size for $0<p_{\ell}<1$. Thus, the equation reflects the particular situation when the tradeoff is successful such that risk neutral individuals would appear to be indifferent between two labor markets that differ only in size.

However, Equation (6) represents a period of length $\lambda_{\mathrm{s}}$ when there is only one job opening in market $s$, but $\alpha>1$ job openings in market $\ell$. Thus, the probability that a worker in market $\ell$ will be employed before the end of the period is positive, and the probability that she will have obtained a job by the end of the period is as high as that of a counterpart in market $s$ (condition represented by Equation (6)). This should make market $\ell$ more attractive for someone who is unemployed, assuming that there is no moving cost associated with making a choice. Thus, Equation (6) understates the requirement for indifference between the two markets and the above argument suggests that $p_{s}>1-\left(1-p_{\ell}\right)^{\alpha}$ would be required. This is an interesting insight that shows that the frequency of intervening opportunities influences labor market choices independently of the mathematical expectation of the unemployment duration. Figure 1 illustrates the tradeoff between $p$ and $\alpha$.

Figure 1 shows that when the economy is so depressed that $p \approx 0$, size does not matter much and when $p=0$, size does not matter at all. Such a situation represents the complete breakdown of an economy. On the other hand, as we have shown in the discussion following Equation (6), when $p=1$, size may still matter because of differences in the frequency of job offerings. This is not reflected in Figure 1 because the underlying mathematical formulation ignores differences in the frequency of intervening opportunities.

It is at intermediate values of $p$ that large labor markets offer job seekers the greatest advantage over smaller ones. Figure 1 also shows that if we hold $p$ constant, $(1-p)^{a}$ (failure to obtain a job during a given period) decreases less as we move from $\alpha=2$ to $\alpha=3$ than from $\alpha=1$ to $\alpha=2$, etc., indicating diminishing returns to the advantage of labor market size. For an empirical study of the influence of economic conditions on unemployment duration, see Arulampalam and Stewart (1995). To gain some intuition about the effect of labor market size, let $p=0.7$. Then, assume a period length of one workweek and let $\lambda=0.2$ (one job opening/workday). Then the expected unemployment duration is 0.29 workweeks, or a bit more than a workday (from Equation (4)). Now consider a smaller market with $\lambda=1$ (one job/workweek), then the expected unemployment duration is 1.43 workweeks or more than eight workdays.

\section{STANDARD DEVIATION OF EXPECTED UNEMPLOYMENT DURATION}

In comparing labor markets, it is not only the expected duration of unemployment, but also the standard deviation that should be considered, as the latter provides a rough measure of the risk of being unemployed.

$$
\sigma(\Lambda)=\sqrt{1-p} \frac{\lambda}{p}
$$




\section{FIGURE 1: Relationship between Labor Market Size and Expected Unemployment Duration}

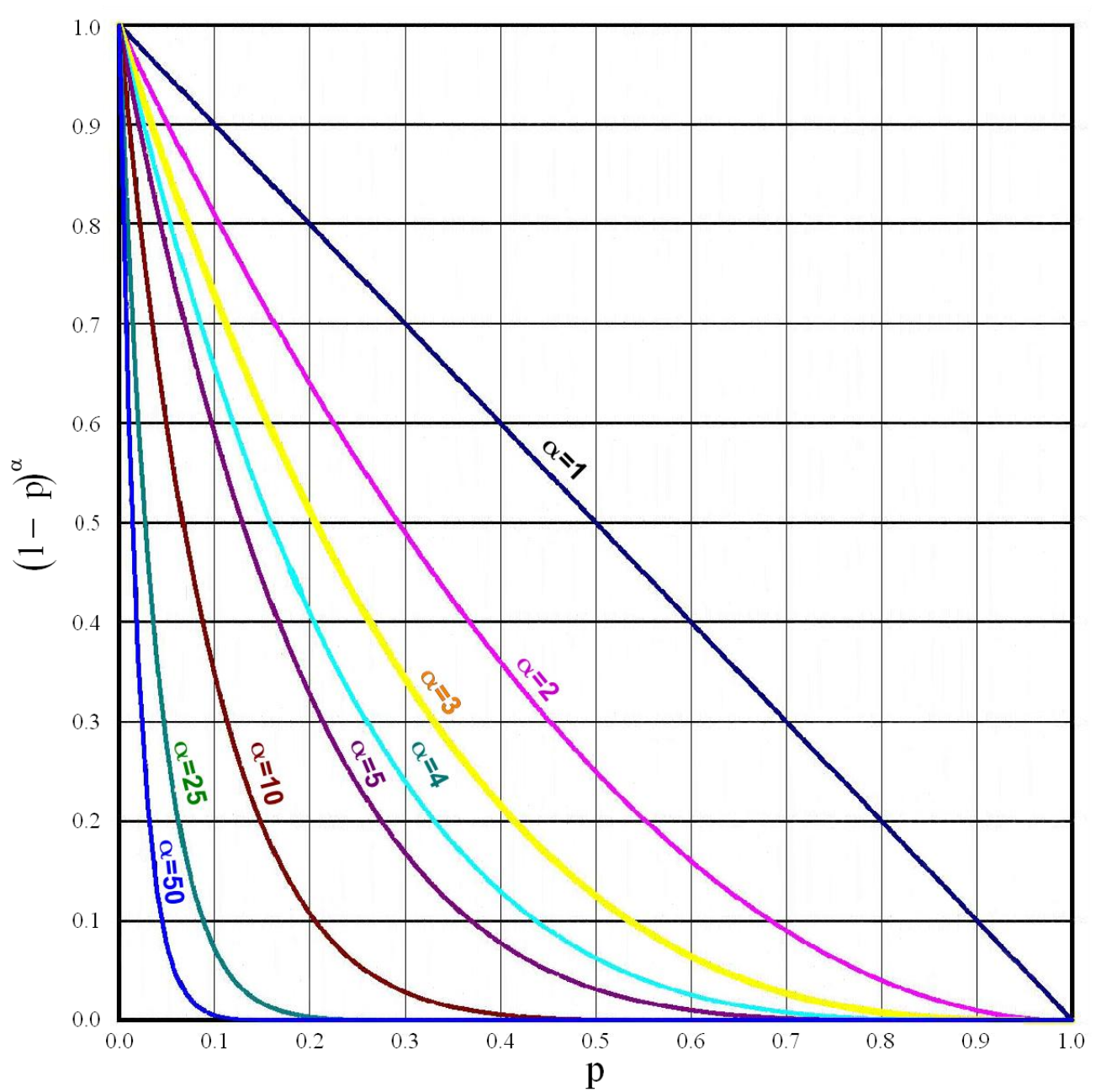

Note: The vertical distance from p-axis to line is the probability of not obtaining a job within a given period. The vertical distance from the line to the top of the graph is the probability of obtaining a job. It is equal to $1-(1-p)^{\alpha}$

Clearly, if the demand for workers is very strong so that $p$ is relatively large, then, particularly in a large market ( $\operatorname{small} \lambda$ ), the standard deviation is small. Of course, if $p=1$, then there is no risk at all, though in a small market the wait for the next job opening that will take the worker off the unemployment roll could still be relatively long. In the case of $0<p<1$, the derivative of the standard deviation of $\Lambda$ with respect to $L$ is indeterminate because it consists of two terms, the first negative and the second positive: 


$$
\frac{d \sigma}{d L}=\underbrace{2 \lambda \frac{1-p}{p} \frac{d \lambda}{d L}}_{\begin{array}{c}
\text { reflects change } \\
\text { in of frequency } \\
\text { of job offers }
\end{array}}+\underbrace{\lambda^{2} \frac{p-2}{p^{3}} \frac{d p}{d L}}_{\begin{array}{c}
\text { reflects change in } \\
\text { probability of job } \\
\text { offer }
\end{array}} .
$$

At first glance this runs counter to intuition. As the frequency of job offers increases with labor market size, for a constant value of $p$, the standard deviation of the expect duration of unemployment should decrease. While this is correct (represented by the first term in Equation (8)), $p$ is not constant but changes with labor market size and counteracts the effect of increasing opportunities. Thus, Equation (8) implies that, in general, the standard deviations in two labor markets of different size will not be the same, even if $E\left[\Lambda_{\mathrm{s}}\right]=E\left[\Lambda_{\ell}\right]$. Since individuals are usually not risk neutral, this result has potentially important empirical implications. Note that because of our assumptions, risk aversion has no effect on $p$, the joint probability of being offered and accepting a job. Thus, the result only reflects labor market size and implies that unless individuals are risk neutral, different labor markets may be chosen in part based on attitudes toward risk.

\section{SUMMARY AND CONCLUSIONS}

In an uncertain world there may be benefits to agglomeration even if labor and employers are homogenous. The model only considers size, but not a labor market's spatial concentration or moving or commuting costs. Rosenthal and Strange (2001) explored the importance of spatial concentration for labor market pooling and found that labor market pooling provides the most robust explanation of agglomeration. Our model deliberately excludes a spatial component so as to only address the issue of size, measured by number of job openings per time period, not of concentration or density.

In a nutshell, the model suggests the possibility that expected unemployment duration, associated standard deviations, and unemployment rates may systematically differ between labor markets, even if labor markets are identical in every respect except size, and labor and employers are both homogenous. The finding that differences among either workers or jobs are not necessary to obtain such a result is not obvious. In addition, our results demonstrate that there are diminishing returns to market size, and that (expected) unemployment duration is an imperfect measure for comparing conditions in different labor markets because it does not capture differences in intervening opportunities. The model also showed that it is possible that two markets can have the same expected unemployment duration and different rates of unemployment, implying that what the unemployment rate says about labor market conditions is incomplete. This finding may explain why the unemployment rate often performs poorly as an explanatory variable, for example in labor migration models (Greenwood, 1975).

We assume that small labor markets can respond by offering better odds in the search for employment. Once they have exhausted this option, however, small markets are at a competitive disadvantage relative to larger markets. However, the model does not allow for adjustments in other variables, such as wages, probability of future layoffs, etc. In the real world, we would expect market participants to respond creatively. For example, Wojan's (2000) study of rural manufacturing during 
market downturns suggests rural firms behaved differently vis-à-vis the subset of their most skilled workers than did their counterparts in urban (larger) markets.

The results obtained here are of interest in migration, labor, and economic development research and complement previous reasons given for the existence of agglomerations. While heterogeneity in labor markets is certainly the most compelling reason, we show that even in its absence incentives for agglomeration may exist.

\section{REFERENCES}

Akerlof, George A. and Brian G.M. Main. (1981) "An Experience-weighted Measure of Employment and Unemployment Durations," American Economic Review, 71, 1003-1011.

Arulampalam, Wiji and Mark Stewart. (1995) "The Determinants of Individual Unemployment Durations in an Era of High Unemployment,” Economic Journal, 105, 321-332.

Bartik, Timothy J. (2002) “Spillover Effects of Welfare Reforms in State Labor Markets," Journal of Regional Science, 42, 667-701.

Berkovitch, Elazar. (1985) "Reputation Effect in Equilibrium Search and Bargaining-A Stigma Theory of Unemployment Duration," Discussion Paper No. 668, Center for Mathematical Studies in Economics and Management Science, Northwestern University.

Bleakley, Hoyt and Jeffrey Lin. (2007) "Thick-market Effects and Churning in the Labor Market: Evidence from U.S. Cities," FRB of Philadelphia Working Paper 07-23, Federal Reserve Bank of Philadelphia.

Dilger, Robert J., Eleanor Blakely, Melissa Latimer, Barry Locke, L. Christopher Plein, Lucinda A. Potter, and David Williams. (2004) "WV Works" Perspectives of Former Recipients Who Have Exhausted Their 60 Months of Program Eligibility," West Virginia Public Affairs Reporter 21(2), 2-20. Available in December 2010 at http://ipa.wvu.edu/r/download/43218.

Fields, Gary S. (1976) "Labor Force Migration, Unemployment and Job Turnover," Review of Economics and Statistics, 58, 407-415.

Gan, Li and Qinghua Zhang. (2006) "The Thick Market Effect on Local Unemployment Fluctuations," Journal of Econometrics, 133, 127-152.

Greenwood, Michael. (1975) "Research on Internal Migration in the United States: A Survey," Journal of Economic Literature, 13, 397-433.

Groen, Jeffrey A. (2005) “Occupation-specific Human Capital and Local Labor Markets,” Working Paper 376, U.S. Department of Labor, Bureau of Labor Statistics, Office of Employment and Unemployment Statistics.

Lockwood, Ben (1991), "Information Externalities in the Labour Market and the Duration of Unemployment," Review of Economic Studies, 58, 733-753.

Marshall, Alfred. (1890, 1920) Principles of Economics ( $8^{\text {th }}$ ed). Macmillen: London.

Mukoyama, Toshihiko and Ayşegül Şahin. (2009) "Why Did the Average Duration of Unemployment become so Much Longer,” Journal of Monetary Economics, 56, 2000-2009. 
Myers, Milton L. (1983) The Soul of Modern Economic Man. Ideas of Self-Interest: Thomas Hobbes to Adam Smith. University of Chicago Press: Chicago.

Neumann, George R. and Robert H. Topel. (1991) "Employment Risk, Diversification, and Unemployment," Quarterly Journal of Economics, 106, 1341-1365.

Rogerson, Richard, Robert Shimer, and Randall Wright. (2005) "Search-theoretic Models of the Labor Market: A Survey,” Journal of Economic Literature, 43, 959-988.

Rosenthal, Stuart S. and William C. Strange. (2001) “The Determinants of Agglomeration,” Journal of Urban Economics, 50, 191-229.

Smith, Adam. (1776, 1965) An Inquiry into the Nature and Causes of the Wealth of Nations. The Modern Library: New York.

U.S. Library of Congress. (1995) Personal Responsibility and Work Opportunity Act of 1995. Last accessed December 2010 at http://frwebgate.access.gpo.gov/cgi-bin/getdoc.cgi ?dbname=104_cong_bills\&docid=f:h4enr.txt.pdf

Wojan, Timothy R. (2000) "Fragile Virtue: Rural Labor Market Response to a New Competitive Environment," Chapter 31 in Peter V. Schaeffer and Scott Loveridge (eds.), Small Town and Rural Economic Development: A Case Studies Approach. Praeger: Westport, CT, pp. 251259. 